\title{
Increased expression of Lgr5 is associated with chemotherapy resistance in human gastric cancer
}

\author{
HONG-QING XI", JIAN-XIN CUI*, WEI-SONG SHEN, XIAO-SONG WU, SHI-BO BIAN, \\ JI-YANG LI, ZHOU SONG, BO WEI and LIN CHEN
}

Department of General Surgery, Chinese People's Liberation Army General Hospital, Beijing 100853, P.R. China

Received February 26, 2014; Accepted April 23, 2014

DOI: $10.3892 /$ or.2014.3207

\begin{abstract}
Leucine-rich repeat-containing G protein-coupled receptor 5 (Lgr5), a marker of adult stem cells and cancer stem cells, plays important roles in tumor progression. Furthermore, Lgr5 also contributes to chemoradiotherapy resistance. However, the function of Lgr5 in the prediction of preoperative chemotherapy efficacy has not been reported. We evaluated the potential of Lgr5 in predicting tumor response and overall survival in advanced gastric cancer treated with preoperative chemotherapy. The association between Lgr5 and chemotherapy resistance was also investigated in gastric cancer cell lines. Hematoxylin and eosin staining and immunohistochemical analysis of Lgr5 expression were performed in 68 cases of gastric cancer treated with preoperative chemotherapy. Lgr5 expression was specifically silenced in the AGS gastric cancer cell lines by RNA interference. Levels of Lgr5 mRNA and protein in cell lines were detected by quantitative reverse transcription-polymerase chain reaction or western blotting. Cell viability was evaluated by an MTT assay. Cell apoptosis was assessed by Annexin V-FITC/propidium iodide dual staining analysis. We found that Lgr5 expression was significantly associated with tumor regression grade after preoperative chemotherapy. The rate of positive Lgr5 expression was significantly higher in patients with poor tumor regression compared with those exhibiting tumor regression $(\mathrm{P}=0.001)$. Lgr5-positive patients had a significantly shorter survival time than Lgr5-negative patients $(\mathrm{P}=0.001)$. Inhibition of Lgr5 expression with small interfering RNA increased the sensitivity of AGS gastric cancer cells to chemotherapy. Our findings suggest that Lgr5 expression may be implicated in the chemoresistance of gastric cancer cells and is a potential novel biomarker for predicting response to chemotherapy and
\end{abstract}

Correspondence to: Professor Lin Chen or Professor Bo Wei, Department of General Surgery, Chinese People's Liberation Army General Hospital, 28 Fuxing Road, Beijing 100853, P.R. China

E-mail: chenlinbj@sina.com

E-mail:weibobj301@sina.com

${ }^{*}$ Contributed equally

Key words: gastric cancer, Lgr5, chemoresistance, prognosis prognosis in gastric cancer patients, and may also represent a potential new therapeutic target for cancer therapy.

\section{Introduction}

Gastric cancer is one of the most frequently occurring aggressive malignancies, and is the second most common cause of cancer-related mortality worldwide (1). The majority of gastric cancer cases are already in the advanced stages when diagnosed and the prognosis is generally poor, with a 5-year survival rate $<30 \%$ (2). Preoperative chemotherapy has been successfully used in the treatment of locally advanced gastric cancer, as it is capable of shrinking the tumor, thereby increasing the possibility of complete resection. Previous studies indicated that this treatment strategy may significantly improve overall survival in patients with resectable gastric cancer (3). However, only $20 \%$ of patients experienced complete or subtotal tumor regression (4), with chemotherapy resistance representing the major obstacle for successful treatment.

Leucine-rich repeat-containing $\mathrm{G}$ protein-coupled receptor 5 (Lgr5), also known as GPR49, is considered a target of Wnt signaling (5-8). Lgr5 is a potential marker of adult stem cells of the small intestine, colon, stomach and hair follicle bulge (9-11). Increased expression of Lgr5 has been investigated in several types of human cancer, including hepatocellular carcinoma (7), gastric (12), colorectal (13-15) and ovarian cancer (16), basal cell carcinoma (17), esophageal adenocarcinoma (18) and brain cancer (19). In colorectal cancer, increased Lgr5 expression was identified in the spheroid cells (20), making it an ideal marker of colorectal cancer stem cells (CSCs) $(13,14)$. It is well documented that CSCs can survive radiation therapy and chemotherapy. Becker et al suggested that Lgr5 may represent a better marker for CSCs in colorectal cancer (21). Previous studies indicated that Lgr5 expression level in rectal cancer specimens was elevated after preoperative chemoradiotherapy (CRT). Moreover, elevated Lgr5 gene expression was associated with poor pathological response and poor survival $(22,23)$ suggesting that Lgr5 may contribute to CRT resistance.

Previous studies identified elevated Lgr5 expression in gastric cancer (21). Furthermore, Lgr5-positive cells were correlated with gastric cancer carcinogenesis and progression (12). Previously, gastric cancer was considered to be a chemosensitive tumor; however, responses to chemotherapy 
were partial and short lived (24). We propose that Lgr5 plays a potential role in chemotherapy resistance in gastric cancer. To our knowledge, no studies investigating the value of Lgr5 expression in the prediction of preoperative chemotherapy efficacy in gastric cancer patients have been reported. In this study, we investigated the potential of Lgr5 as a specific biomarker in predicting tumor response and overall survival in advanced gastric cancer patients treated with preoperative chemotherapy. Furthermore, the possible association between Lgr5 expression and chemotherapy resistance was also investigated.

\section{Materials and methods}

Patients and specimens. A total of 68 patients with gastric cancer were included in this study. All patients had undergone preoperative (oxaliplatin-based) chemotherapy followed by gastrectomy between 2007 and 2009 in the Chinese People's Liberation Army (PLA) General Hospital (Beijing, China). All patients received three cycles of oxaliplatin-based adjuvant chemotherapy, including 56 patients treated with oxaliplatin/leucovorin/5-fluorouracil (5-FU) [FOLFOX4, oxaliplatin $\left(85 \mathrm{mg} / \mathrm{m}^{2}\right)$ and leucovorin $\left(400 \mathrm{mg} / \mathrm{m}^{2}\right)$ followed on days 1 and 2 by 5 -FU $\left(400 \mathrm{mg} / \mathrm{m}^{2}\right)$ administered by intravenous (i.v.) bolus, then subsequently $\left(600 \mathrm{mg} / \mathrm{m}^{2}\right)$ over a 22 -h continuous infusion] repeated every 2 weeks, and 12 patients treated with S-1/oxaliplatin [SOX, oxaliplatin $\left(130 \mathrm{mg} / \mathrm{m}^{2}\right)$ administered by i.v. injection on day 1 , with S-1 administered orally $(80 \mathrm{mg} /$ $\mathrm{m}^{2} /$ day) for 14 days] repeated every 3 weeks. Patient eligibility was based on fulfillment of the following institute criteria: i) patients had received no previous radiotherapy or immunotherapy, ii) performance status was 0-2 (Eastern Cooperative Oncology Group scale) (25), iii) aged between 18 and 79 years, and iv) clinical tumor was stage II or III according to clinical TNM stage revised by the International Union Against Cancer (UICC) in 2009, with no evidence of distant metastases. Pre-treatment endoscopic biopsy specimens and surgically resected tumors were routinely fixed in $10 \%$ formalin and embedded in paraffin wax. Tissue sections were stained with hematoxylin and eosin (HE). Histopathological features and responsiveness to neoadjuvant chemotherapy were evaluated by light microscopy. All patients were followed up for survival analysis. The follow-up period was calculated from the date of surgery until June 30, 2012.

Histological assessment of chemotherapeutic effects. Histological slides were independently reviewed by two pathologists blinded to all clinical pathology data. In the event of discordant observations, the slides were reassessed on a double-headed microscope to establish a final result. Postchemotherapy, histological tumor regression grading (TRG) was evaluated according to the Becker et al score (26), based on an estimation of the percentage of vital tumor tissue in relation to the macroscopically identifiable tumor bed that was evaluated. Tumor regression was classified into three categories: TRG 1, complete or subtotal regression $(<10 \%$ residual tumor/tumor bed); TRG 2, partial tumor regression (10-50\% residual tumor/tumor bed) and TRG 3, minimal or no tumor regression ( $>50 \%$ residual tumor/tumor bed). All patients with grade 1 and 2 regression were classified as responders, while patients with grade 3 regression were defined as pathologic non-responders. Specimens with no residual cancer cells and only a fibrotic mass were excluded, as our immunohistochemical staining targeted residual cancer tissue.

Immunohistochemistry. Immunohistochemical staining of Lgr5 was performed as previously described (27). Sections ( $4 \mu \mathrm{m})$ were cut from paraffin-embedded tissue blocks, deparaffinized in xylene and rehydrated. Antigen retrieval was performed by heating in $0.01 \mathrm{~mol} / \mathrm{l}$ citrate buffer $(\mathrm{pH} 6.0)$ in a microwave oven for $2 \mathrm{~min}$ at $100^{\circ} \mathrm{C}$. Sections were subsequently incubated with $3 \%$ hydrogen peroxidase-methanol for $15 \mathrm{~min}$ to inhibit endogenous peroxidase activity. After washing with phosphate-buffered saline (PBS), and blocking with $10 \%$ goat serum, sections were incubated with primary monoclonal rabbit antibody to human Lgr5 (1:50 in blocking solution; Abcam, Cambridge, MA, USA) or PBS (negative control) and incubated overnight at $4^{\circ} \mathrm{C}$. Slides were subsequently washed three times with PBS and incubated for $30 \mathrm{~min}$ with biotinylated secondary antibody (polyperoxidase-antimouse/rabbit IgG; Zymed Laboratories, San Francisco, CA, USA). Peroxidase reactivity was visualized using a 3,3'-diaminobenzidine (DAB) substrate kit (Zymed Laboratories) and slides were counterstained with hematoxylin.

Evaluation of immunohistochemistry. Immunohistochemical sections were independently reviewed by two experienced pathologists with no prior knowledge of patient pathology data. In discrepant cases, a final score was established by reassessment of section on a double-headed microscope. Lgr5 expression was evaluated according to a score incorporating both staining intensity and the percentage of cells stained (28). Staining intensity was scored as follows: 0 , no staining; $1+$, weak staining; $2+$, moderate staining; and $3+$, intense staining. The percentage of staining was scored as follows: 0 , no staining in all cells; $1+$, positive staining in $<10 \%$ of cells; $2+$, positive staining in $10-50 \%$ cells; and $3+,>50 \%$ positive staining. The final score was determined by the combined staining score. A score (extent + intensity) $\leq 1$ was considered negative and a score between 2 and 6 was considered positive $(29,30)$.

Cell culture. Previously, we demonstrated that Lgr5 levels were significantly higher in the gastric cancer cell lines (MGC803, SGC7901, AGS, BGC823, MKN45) than in the gastric epithelial cell line (GES-1). Lgr5 expression was the highest in AGS cells, which were selected for subsequent RNA interference experiments. The AGS human gastric carcinoma cell line was purchased from the American Type Culture Collection (ATCC; Manassas, VA, USA). Cells were cultured in RPMI-1640 medium supplemented with $10 \%$ fetal bovine serum (both from Gibco-BRL, Gaithersburg, MD, USA), $100 \mathrm{U} / \mathrm{ml}$ penicillin and $100 \mu \mathrm{g} / \mathrm{ml}$ streptomycin. Cells were cultured and passaged at $37^{\circ} \mathrm{C}$ in culture flasks with a humidified atmosphere of $5 \% \mathrm{CO}_{2}$.

Transient transfection of Lgr5 small interfering RNAs (siRNAs). siRNAs were synthesized by GenePharma Co. (Shanghai, China). The sequences were as follows: 5'-GCAGA AUAAUCAGCUAAGATT-3' (sense), and 5'-UCUUAGCUGA UUAUUCUGCTT-3' (antisense); Lgr5-homo-1555, 5'-GGAC 
GACCUUCAUAAGAAATT-3' (sense), and 5'-UUUCUUAU GAAGGUCGUCCTT-3' (antisense); Lgr5-homo-2664, 5'-GC UCCAGCAUCACUUAUGATT-3' (sense), and 5'-UCAUAAG UGAUGCUGGAGCTT-3' (antisense); negative control, 5'-UUCUCCGAACGUGUCACGUTT-3' (sense), and 5'-ACG UGACACGUUCGGAGAATT-3' (antisense); GAPDH positive control, 5'-GUAUGACAACAGCCUCAAGTT-3' (sense), and 5'-CUUGAGGCUGUUGUCAUACTT-3' (antisense).

AGS cells were cultured in 6-well plates and were then transiently transfected with $4 \mu \mathrm{l}$ of siRNA using $2 \mu \mathrm{l}$ of Lipofectamine 2000 (Invitrogen, USA), according to the manufacturer's instructions.

Cell viability assay. Transfected AGS cells were seeded in 96-well plates ( $1 \times 10^{4}$ cells/well). After $24 \mathrm{~h}$, cells were exposed to increasing concentrations of oxaliplatin, $0.1-10 \mu \mathrm{g} / \mathrm{ml}$, or to 5-FU (0.25-20 $\mu \mathrm{g} / \mathrm{ml}$; both from Sigma, St. Louis, MO, USA) for $72 \mathrm{~h}$, and cell viability was assessed by MTT assay. MTT reagent ( $20 \mu \mathrm{l}$ of a $5 \mathrm{mg} / \mathrm{ml}$ stock) was added into each well and incubated at $37^{\circ} \mathrm{C}$, in a humidified atmosphere of $5 \% \mathrm{CO}_{2}$. After $4 \mathrm{~h}$, this mixture was carefully removed and $150 \mu \mathrm{l}$ of dimethyl sulfoxide was added to each well and plates were incubated on a rocking shaker for $10 \mathrm{~min}$. Absorbance was measured at a wavelength of $490 \mathrm{~nm}$ with a microplate reader and the background absorbance of the medium in the absence of cells was subtracted. The cell survival rate $(\%)$ was calculated as follows: Survival rate $(\%)=($ mean A value of drug-treated group - mean A value of blank control group)/(mean A value of the negative control group - mean A value of blank control group) $\mathrm{x} 100 \%$. Each assay was performed in triplicate, and the results are presented as the means \pm standard deviation (SD).

Quantitative real-time reverse transcription-polymerase chain reaction ( $q R T-P C R)$. Total RNA was extracted from cells using an RNeasy Mini kit (Qiagen, Tokyo, Japan) and reverse transcribed using a cDNA reverse transcription kit (Applied Biosystems, Foster City, CA, USA). qRT-PCR analysis was performed on an ABI PRISM 7700 Sequence Detection System using SYBR-Green PCR Master Mix (both from Applied Biosystems) and the following cycling conditions: $95^{\circ} \mathrm{C}$ for $10 \mathrm{~min}$, followed by 50 cycles of $95^{\circ} \mathrm{C}$ for $15 \mathrm{sec}$ and $60^{\circ} \mathrm{C}$ for $1 \mathrm{~min}$. Amplification was performed using the following primer sets: Lgr5 (NM_003667.2) (161 bp), forward primer 5'-TTTGGACAAGGGAGACCTGGAGAAT-3', and reverse primer 5'-GAAAGCCACAGGGCAGTTTAGGAT-3'; MMP2 (NM_001127891) (160 bp), forward primer 5'-AGCA TGTCCCTACCGAGTCT-3', and reverse primer, 5'-AAACAG ATGGCAAACACGGC-3'; GAPDH (266 bp), forward primer 5'-AGAAGGCTGGGGCTCATTTG-3', and reverse primer, 5'-AGGGGCCATCCACAGTCTTC-3'. Relative transcript levels were calculated using the $2^{-\Delta \Delta \mathrm{C}_{\mathrm{T}}}$ method (31). $L g r 5 \mathrm{mRNA}$ expression levels were normalized to those of GAPDH. All experiments were performed in biological triplicate.

Western blot analysis. BGC-823 and AGS cells were lysed in RIPA lysis buffer, and cell lysates were clarified by centrifugation $\left(13,000 \mathrm{rpm}, 4^{\circ} \mathrm{C}, 20 \mathrm{~min}\right)$. The concentration of protein lysates was assessed using the Bradford method (Bio-Rad, Hercules, CA, USA). Equal quantities of protein
(50 $\mu \mathrm{g} /$ lane) were then separated by $12 \%$ sodium dodecyl sulfate-polyacrylamide gel electrophoresis (SDS-PAGE), and transferred to nitrocellulose membranes (Amersham Biosciences, Piscataway, NJ, USA). After blocking with $5 \%$ non-fat milk in TBS-T $[50 \mathrm{mmol} / \mathrm{L}$ Tris- $\mathrm{HCl}(\mathrm{pH} 7.6)$, $150 \mathrm{mmol} / 1 \mathrm{NaCl}, 0.1 \%$ Tween-20] at room temperature for $1 \mathrm{~h}$, membranes were incubated with primary antibodies (antiLgr5, 1:100; anti-GAPDH, 1:1,500; Abcam, Cambridge, MA, USA) in blocking buffer overnight at $4^{\circ} \mathrm{C}$. After washing three times with TBS-T, membranes were incubated with a horseradish peroxidase-coupled goat anti-rabbit secondary antibody (1:2,000; Santa Cruz Biotechnology) for $2 \mathrm{~h}$ at room temperature. Bands were visualized by chemiluminesence. The protein quantity using Quantity One v4.4 software (Bio-Rad). Target protein expression was evaluated by the relative intensity ratio of target protein-to- $\beta$-actin loading control.

Apoptosis analysis with Annexin V-FITC/propidium iodide (PI) dual staining. Apoptosis was quantified by dual staining with Annexin V and PI using the Annexin V-FITC apoptosis detection kit (Biosea Biotechnology, Beijing, China). All gastric cancer cell lines $\left(2 \times 10^{5}\right.$ cells/well) were cultured in 6-well plates to $70-80 \%$ confluence. Cells were then treated with the indicated concentrations of oxaliplatin or 5-FU for $24 \mathrm{~h}$. Cells were harvested and washed with ice-cold PBS (x3) and resuspended in $200 \mu 1 \mathrm{XX}$ binding buffer. Annexin V-FITC $(10 \mu \mathrm{l})$ and PI $(5 \mu \mathrm{l})$ were then added and cells were incubated for $15 \mathrm{~min}$ at room temperature in the dark. Cells were analyzed by flow cytometry using a FACSAria cytometer (Becton-Dickinson, San Jose, CA, USA). All experiments were performed in biological triplicate.

Statistical analysis. Statistical analyses were performed using SPSS V.13.0 (SPSS, Inc., Chicago, IL, USA). The Pearson $\chi^{2}$ test was used to examine the various clinicopathological characteristics and TRG with the expression of Lgr5. Cumulative survival curves were drawn by the Kaplan-Meier method. The difference between the curves was analyzed by the log-rank test. Multivariate survival analysis was based on the Cox proportional hazard model. The data of cell survival rate are presented as the means \pm SD of at least three independent experiments. Differences of the variables between groups were analyzed by the Student's t-test. A value of $\mathrm{P}<0.05$ was considered statistically significant.

\section{Results}

Patients and tumor characteristics. A total of 68 patients with gastric cancer, aged between 31 and 79 years (median, 62.5 years; mean, 58.5 years) were enrolled in this study. These included 36 cases of well or moderately differentiated adenocarcinoma and 32 cases of poorly differentiated, signet ring cell, or mucinous adenocarcinoma. The post-chemotherapy, pathological $\mathrm{T}$ stages were $\mathrm{ypT}_{0-2}(\mathrm{n}=32)$ and $\mathrm{ypT}_{3+4}$ $(\mathrm{n}=36)$. Forty-five patients exhibited lymph node metastases. Histological TRG was as follows: TRG 1, 28 patients (41.2\%); TRG 2, 15 patients (22.0\%) and TRG 3, 25 patients (36.8\%) (Table I). During the follow-up period, 37 patients died while 31 patients remained alive (median survival time, 48 months; mean survival time, $45.8 \pm 6.2$ months). Representative HE 
A

Before neoadjuvant chemotherapy
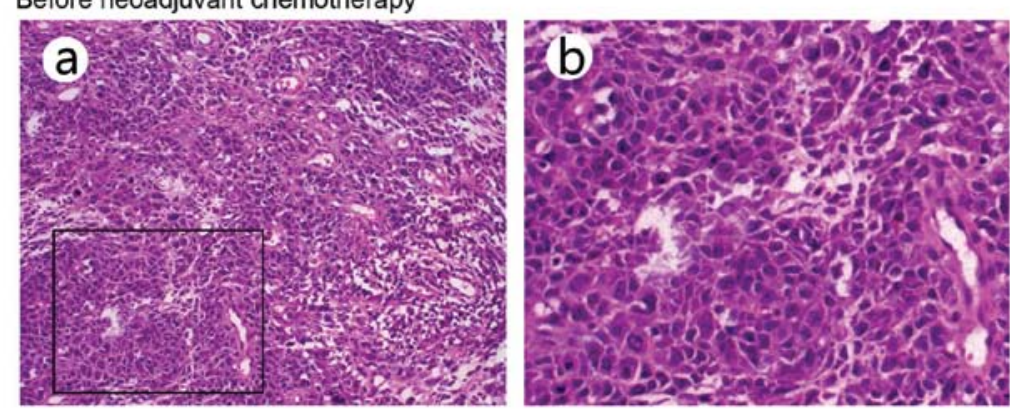

After neoadjuvant chemotherapy
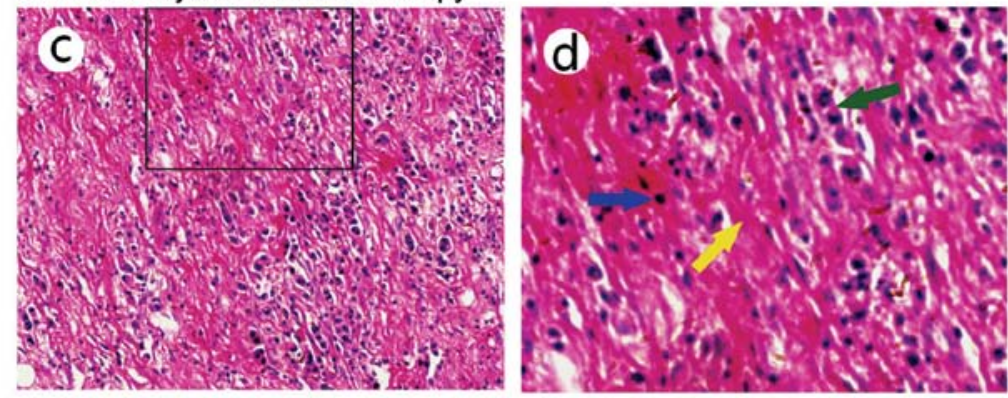

B
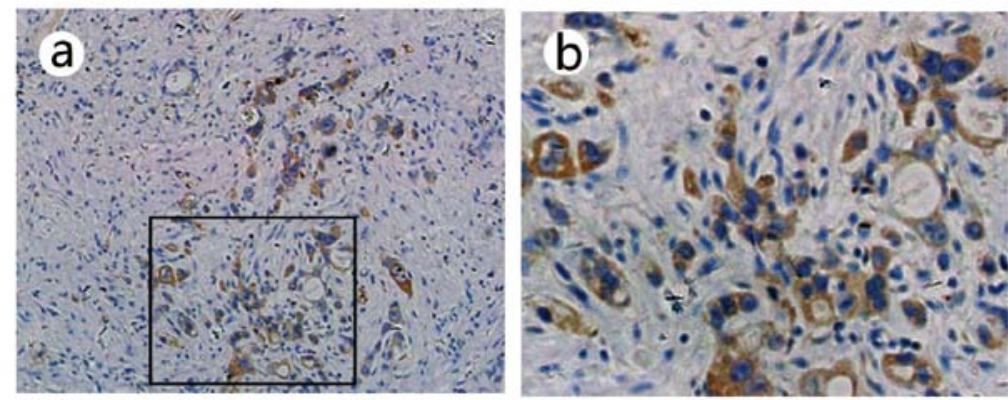

Figure 1. (A) Hematoxylin and eosin (HE) staining patterns in a pre-treatment endoscopic biopsy specimen (a and b) and the resected tumor (c and d) from a representative gastric cancer patient who responded to neoadjuvant SOX chemotherapy. Chemotherapy-induced histological changes including the degeneration of cancer cells with marked inflammatory cell infiltration (blue arrow), fibrosis (yellow arrow), and significantly reduced cancer cells were noted in the resected tumor compared with the pre-treatment biopsy specimen. The green arrow indicates residual cancer cells (a and c, magnification, x100; b and d, magnification, x200). (B) Immunohistochemical analysis of Lgr5 expression in residual cancer cells. Immunoreactive Lgr5 protein was located in the cytoplasm (a, magnification, x100; b, magnification, x200). Lgr5, leucine-rich repeat-containing G protein-coupled receptor 5.

staining patterns in the pre-treatment endoscopic biopsy specimens and surgically resected tumors are shown in Fig. 1A.

Correlation of Lgr5 expression in residual cancer cells with clinicopathological variables. Lgr5 expression was observed in the cytoplasm of residual cancer cells (Fig. 1B). A significant correlation was observed between Lgr5 immunoreactivity and histological differentiation $(\mathrm{P}=0.001)$. Lgr5 expression was more frequently observed in advanced ypT-stage cancer $(\mathrm{P}=0.008)$. Furthermore, $\mathrm{Lgr} 5$ expression positively correlated with metastasis in the regional lymph nodes $(\mathrm{P}=0.001)$ and with progression of the ypTNM stage $(\mathrm{P}=0.001)$. Lgr5 expression was also significantly associated with TRG after preoperative chemotherapy. Finally, patients with poor tumor regression exhibited a significantly higher rate of positive Lgr5 expression than patients with regressed tumors $(\mathrm{P}=0.001)$ (Table I).

Survival analysis. Survival analysis by log-rank test revealed that Lgr5-positive patients had a significantly shorter survival time (median, 31 months; mean, $31.29 \pm 5.92$ months)

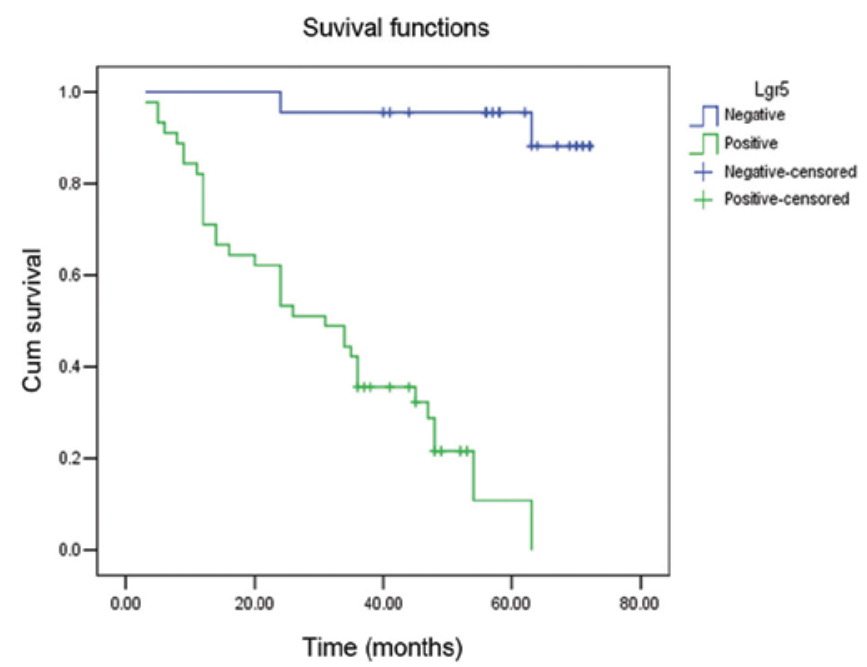

Figure 2. Kaplan-Meier survival curves of gastric cancer patients based on Lgr5 expression levels. Lgr5-positive patients exhibited significantly shorter survival than Lgr5-negative patients, as assessed by the log-rank test $(\mathrm{P}=0.001)$. Lgr5, leucine-rich repeat-containing $\mathrm{G}$ protein-coupled receptor 5. 
Table I. Correlation between Lgr5 expression and clinicopathological features in gastric carcinoma.

\begin{tabular}{|c|c|c|c|}
\hline \multirow[b]{2}{*}{ Variables } & \multicolumn{2}{|c|}{ Lgr5 } & \multirow[b]{2}{*}{ P-value } \\
\hline & $\begin{array}{c}\text { Positive } \\
(\%)\end{array}$ & $\begin{array}{c}\text { Negative } \\
(\%)\end{array}$ & \\
\hline Gender & & & 0.867 \\
\hline Male & $36(66.7)$ & $18(33.3)$ & \\
\hline Female & $9(64.3)$ & $5(35.7)$ & \\
\hline Age (years) & & & 0.582 \\
\hline$<45$ & $5(83.3)$ & $1(16.7)$ & \\
\hline$\geq 45$ and $<60$ & $26(66.7)$ & $13(33.3)$ & \\
\hline$\geq 60$ & $14(60.9)$ & $9(39.1)$ & \\
\hline Tumor size $(\mathrm{cm})$ & & & 0.011 \\
\hline $\mathrm{d}<4$ & $7(41.2)$ & $10(58.8)$ & \\
\hline $\mathrm{d} \geq 4$ and $<8$ & $30(69.8)$ & $13(30.2)$ & \\
\hline $\mathrm{d} \geq 8$ & $8(100)$ & $0(0.0)$ & \\
\hline Histology & & & 0.001 \\
\hline Well/moderate & $17(47.2)$ & $19(52.8)$ & \\
\hline Poor/signet/mucinous & $28(87.5)$ & $4(12.5)$ & \\
\hline ypT category & & & 0.008 \\
\hline $\mathrm{ypT}_{0-2}$ & $16(50.0)$ & $16(50.0)$ & \\
\hline $\mathrm{ypT}_{3+4}$ & $29(80.6)$ & $7(19.4)$ & \\
\hline ypN category & & & 0.001 \\
\hline $\mathrm{ypN}_{0}$ & $7(30.4)$ & $16(69.6)$ & \\
\hline $\mathrm{ypN}_{1-3}$ & $38(84.4)$ & $7(15.6)$ & \\
\hline Postoperative & & & 0.001 \\
\hline TNM stage & & & \\
\hline $\mathrm{I} / \mathrm{II}$ & $16(42.1)$ & $22(57.94)$ & \\
\hline III & $29(96.7)$ & $1(3.3)$ & \\
\hline $\begin{array}{l}\text { Tumor regression } \\
\text { grading }\end{array}$ & & & 0.001 \\
\hline TRG 1 & $8(28.6)$ & $20(71.4)$ & \\
\hline TRG 2 & $13(86.7)$ & $2(13.3)$ & \\
\hline TRG 3 & $24(96.0)$ & $1(4)$ & \\
\hline
\end{tabular}

$\mathrm{P}<0.05$, statistically significant. Lgr5, leucine-rich repeat-containing $\mathrm{G}$ protein-coupled receptor 5 .

compared with Lgr5-negative patients (median, 63 months; mean, 69.25 \pm 4.13 months) (log-rank=33.12, $\mathrm{P}=0.001$ ) (Fig. 2). Multivariate analysis using the Cox regression model revealed that Lgr5 expression significantly affected the outcome of gastric cancer after preoperative chemotherapy and appeared to be an independent prognostic factor $(\mathrm{P}=0.039)$ (hazard ratio $=6.270,95 \%$ confidence interval $=1.097-35.829)($ Table II $)$.

Silencing of Lgr5 expression in gastric cancer cells. To specifically silence Lgr5 expression in gastric cancer cells, three siRNA duplexes targeting different coding regions of the Lgr5 mRNA (Lgr5-homo-409, Lgr5-homo-1555 and Lgr5-homo-2664) were designed and synthesized. siRNAs were transiently transfected into AGS gastric cancer cell lines,
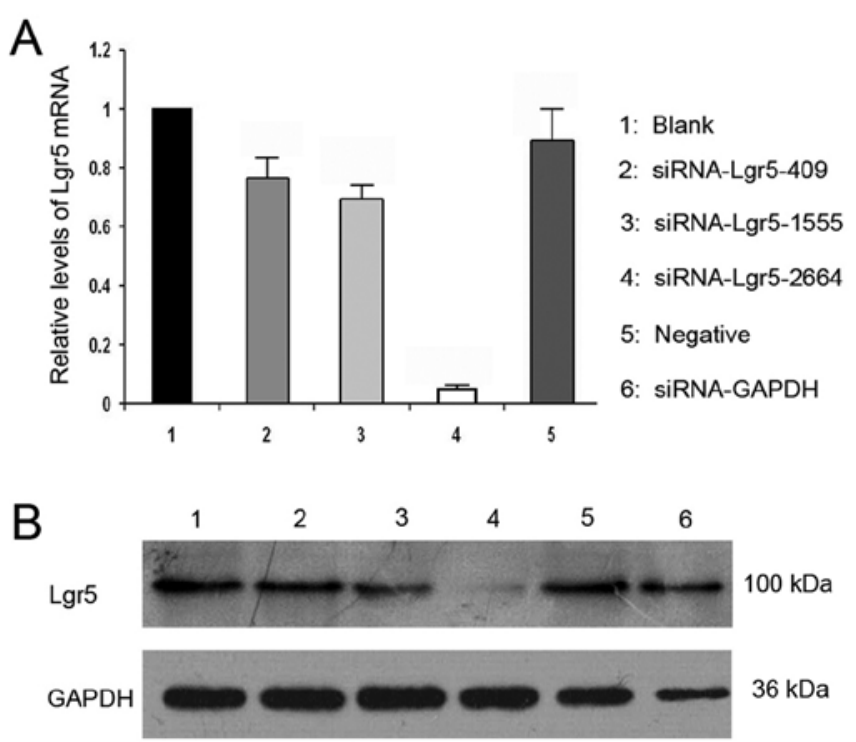

Figure 3. Suppression of Lgr5 expression by siRNA in AGS gastric cancer cells. AGS cells were seeded into 6-well plates and transfected with siRNAs targeting Lgr5 (siRNA-Lgr5-409, siRNA-Lgr5-1555 and siRNA-Lgr5-2664) or scrambled siRNA (negative control). Untransfected cells served as a blank control. Lgr5 mRNA and protein expression were significantly inhibited in siRNA-transfected cells. The Lgr5-homo-2664 siRNA exerted the greatest inhibitory effects. Experiments were performed in biological triplicate with similar results. Lgr5 mRNA levels are presented as mean \pm standard deviation (SD) using GAPDH as an internal control. Lgr5, leucine-rich repeat-containing $\mathrm{G}$ protein-coupled receptor 5 .

and the expression of lgr5mRNA and protein was examined by qRT-PCR and western blot analysis, respectively. The Lgr5-homo-2664 siRNA exhibited the highest Lgr5 silencing efficiency (Fig. 3). The siRNA (Lgr5-homo-2664) was transfected into AGS cells, and the transfectants were then selected for further experiments.

RNAi-mediated downregulation of Lgr5 decreases resistance to oxaliplatin or 5-FU in gastric cancer cells. To investigate whether Lgr5 is associated with chemosensitivity in gastric cancer cells, the effects of silencing Lgr5 expression on oxaliplatin or 5-FU sensitivity in AGS cells was examined by an MTT assay. RNAi-mediated suppression of Lgr5 in AGS cells led to a significant decrease in cell survival rate following treatment with oxaliplatin $(0.1-10 \mu \mathrm{g} / \mathrm{ml})$ compared with the blank and negative control groups (all $\mathrm{P}=0.001$ ) (Fig. 4A). Furthermore, we observed a significant decrease in the survival rate of Lgr5-silenced AGS cells following treatment with 5-FU $(0.25-20 \mu \mathrm{g} / \mathrm{ml})(\mathrm{P}=0.001)$ (Fig. 4B). These results suggest that downregulation of Lgr5 in gastric cancer cells may increase sensitivity to the cytotoxic effects of oxaliplatin or 5-FU.

Effect of Lgr5 interference on AGS cell apoptosis induced by oxaliplatin or 5-FU. The effect of modulating Lgr5 expression on oxaliplatin or 5-FU-induced cell apoptosis was next examined by Annexin V-FITC/PI dual staining analysis (Fig. 5). The rate of apoptosis was significantly higher in AGS cells transfected with Lgr5 siRNA following treatment with $(22.08 \% \pm 1.95)$ compared with the blank group $(9.83 \% \pm 0.72)$ and the negative control group $(10.02 \% \pm 1.22)$ (all $\mathrm{P}=0.001)$. 
A

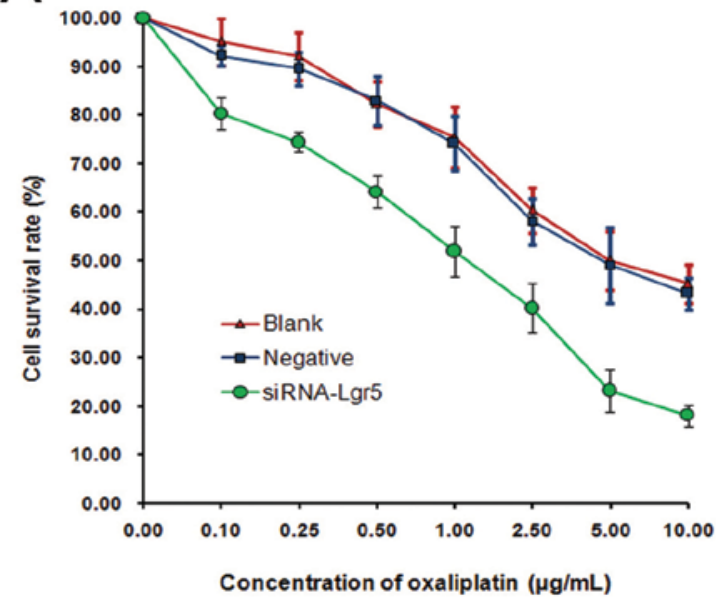

B

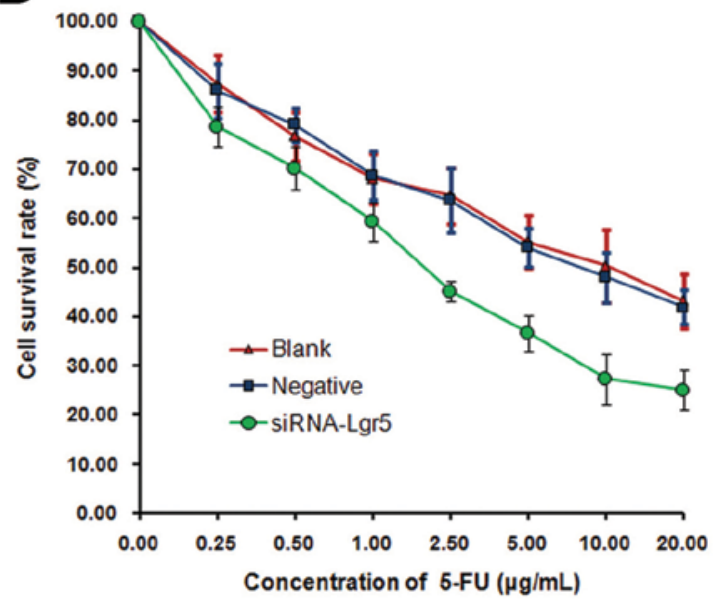

Figure 4. Growth inhibition of gastric cancer cells following treatment with oxaliplatin or 5-FU (A and B). AGS cells were treated with increasing concentrations of oxaliplatin or 5-FU for $72 \mathrm{~h}$ and cell viability was determined by an MTT assay. Each bar represents the means \pm SD. Experiments were performed in biological triplicate with similar results. The survival rate of AGS cells was significantly decreased in Lgr5 siRNA-transfected cells following treatment with oxaliplatin or 5-FU (all P=0.001). 5-FU, 5-fluorouracil; Lgr5, leucine-rich repeat-containing G protein-coupled receptor 5.
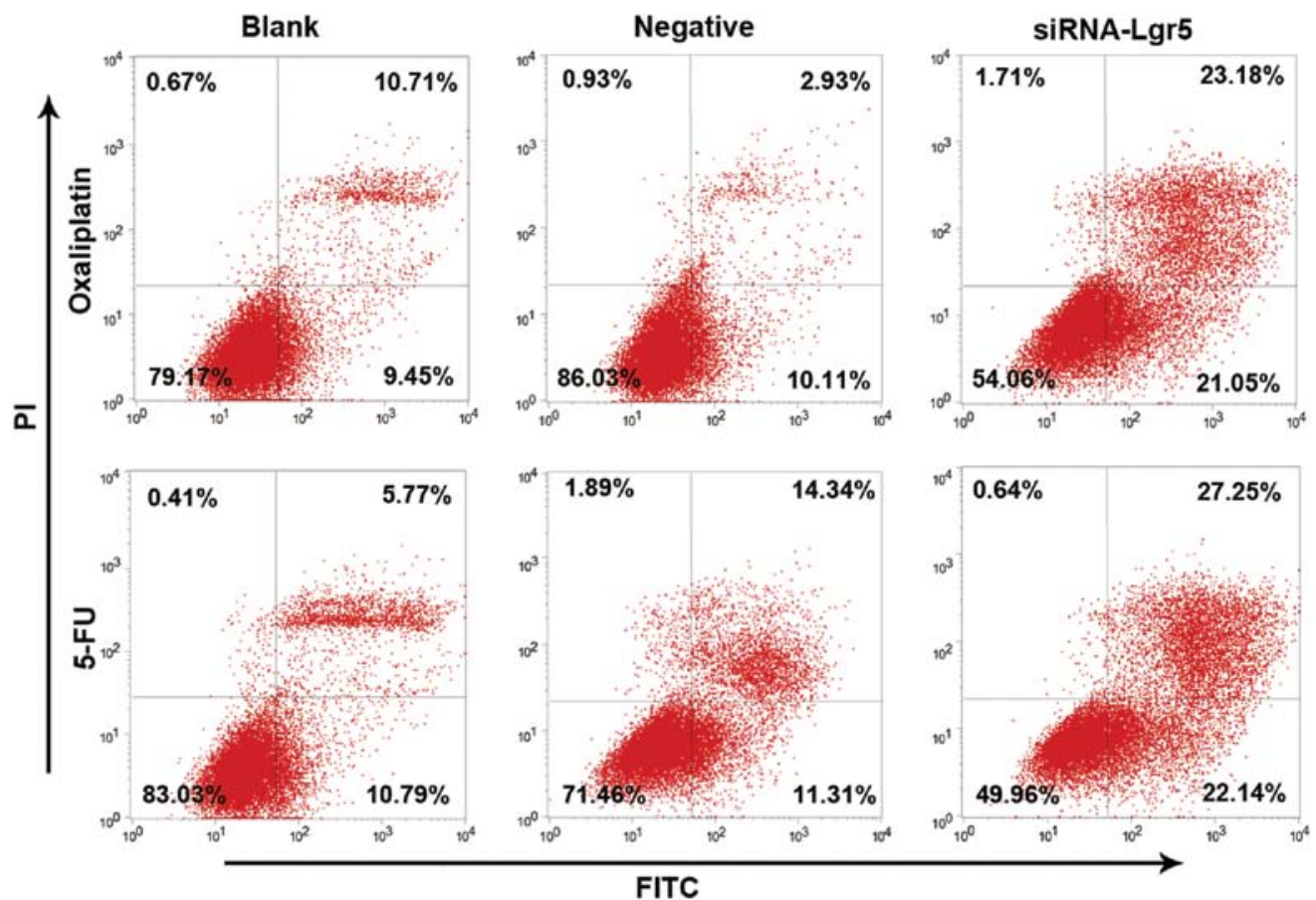

Figure 5. Annexin V-FITC/PI dual staining analysis of AGS cell apoptosis following oxaliplatin or 5-FU treatment. The rate of apoptosis was significantly higher in Lgr5-siRNA-transfected AGS cells following treatment with oxaliplatin or 5-FU compared with the blank and the negative control groups (all $\mathrm{P}=0.001)$. 5-FU, 5-fluorouracil; Lgr5, leucine-rich repeat-containing $\mathrm{G}$ protein-coupled receptor 5 .

No significant difference was observed between the blank and the negative control groups. Similar trends in apoptosis were observed following treatment with 5-FU. The AGS transfected with Lgr5 siRNA cell group exhibited significantly higher rates of apoptosis $(24.15 \% \pm 2.56)$ compared with those in the blank $(10.87 \% \pm 1.24)$ and negative control $(11.56 \% \pm 1.43)$ groups (all $\mathrm{P}=0.001$ ). No significant difference was observed between the blank and the negative control group. Taken together, these results indicate that the inhibition of Lgr5 expression in gastric cancer cells using RNA interference technology may promote sensitivity to chemotherapy in gastric cancer cells.

\section{Discussion}

Gastric cancer remains a major health problem worldwide (4). To date, a number of strategies exist for the treatment of gastric cancer, including preoperative chemotherapy followed by surgery, which is now increasingly used. Patients who respond to preoperative chemotherapy have a significantly longer survival time than non-responders (2). However, response rates are very low $(\sim 20 \%)$ (32), and this is mostly attributed to chemotherapy resistance. CSCs, capable of surviving chemotherapy, may play an important role in this process (33-35). 
Table II. Cox regression analysis of prognostic factors in gastric carcinoma after preoperative chemotherapy.

$95.0 \% \mathrm{CI}$ for HR

\begin{tabular}{|c|c|c|c|c|c|c|c|}
\hline \multirow[b]{2}{*}{ Variables } & \multirow[b]{2}{*}{ B } & \multirow[b]{2}{*}{ SE } & \multirow{2}{*}{$\begin{array}{l}\text { Wald } \\
\text { value }\end{array}$} & \multirow[b]{2}{*}{ P-value } & \multirow[b]{2}{*}{ HR } & \\
\hline & & & & & & Lower & Upper \\
\hline Gender & -0.419 & 0.453 & 0.853 & 0.356 & 0.658 & 0.271 & 1.600 \\
\hline Age & 0.251 & 0.365 & 0.472 & 0.492 & 1.285 & 0.629 & 2.625 \\
\hline Histology & 1.533 & 0.470 & 10.635 & 0.001 & 4.630 & 1.843 & 11.630 \\
\hline Size & 0.092 & 0.344 & 0.071 & 0.790 & 1.096 & 0.558 & 2.150 \\
\hline ypT category & 0.423 & 0.441 & 0.920 & 0.337 & 1.526 & 0.643 & 3.620 \\
\hline ypN category & 0.886 & 0.805 & 1.211 & 0.271 & 2.425 & 0.500 & 11.751 \\
\hline ypTNM stage & 1.513 & 0.598 & 6.408 & 0.011 & 4.540 & 1.407 & 14.645 \\
\hline TRG & 0.623 & 0.640 & 0.947 & 0.330 & 1.864 & 0.532 & 6.532 \\
\hline Lgr5 & 1.836 & 0.889 & 4.261 & 0.039 & 6.270 & 1.097 & 35.829 \\
\hline
\end{tabular}

B, partial regression coefficient; SE, standard error; HR, hazard ratio; Lgr5, leucine-rich repeat-containing G protein-coupled receptor 5; wald value, statistic for $(\mathrm{B} / \mathrm{SE})^{2}$. $\mathrm{P}<0.05$, statistically significant.

Lgr5, a member of the G-protein-coupled receptor (GPCR) superfamily, is a known downstream target gene activated by Wnt signaling and a stem cell marker in the hair-follicle, intestine, colon and stomach (9-11). Lgr5 has also been reported as a marker of colorectal CSCs $(13,14)$. Recent studies reported that rectal cancer specimens from patients with a poor pathological response had significantly higher Lgr5 expression levels than those exhibiting a positive response after CRT. This suggests that Lgr5 expression may be implicated in resistance to CRT in rectal cancer $(22,23)$.

Previously, it was suggested that $\mathrm{Lgr}^{+}$pyloric stem cells may represent a potential cell of origin in Wnt-driven gastric cancer (11). Moreover, Lgr5 expression levels were much higher in gastric cancer than in normal mucosa (12). However, to date, there has been no investigation into the relationship between Lgr5 expression and chemotherapy resistance.

In the present study, we observed that elevated Lgr5 expression in gastric cancer after preoperative chemotherapy was significantly associated with histological differentiation, ypT-stage and postoperative TNM stage. Positive expression of Lgr5 in gastric cancer specimens was associated with poor pathological response to chemotherapy. Additionally, elevated expression of Lgr5 in gastric cancer was significantly correlated with poor survival. These results suggest that Lgr5 may be a useful prognostic factor for gastric cancer after preoperative chemotherapy and may also predict patient response to preoperative chemotherapy. We also examined the biological role of Lgr5 in oxaliplatin resistance of gastric cancer cells following either overexpression or targeted silencing of Lgr5. Analysis of cell growth by an MTT assay revealed a significant decrease in AGS cell survival following suppression of Lgr5. This suggests that Lgr5 increases chemotherapy resistance in gastric cancer cells. There is a relative increase in the frequency of CSCs after chemotherapy as, similar to normal stem cells, CSCs are more resistant to chemotherapy compared with other more differentiated cancer cells. Therefore, Lgr5, a cancer stem cell marker in post-chemotherapy specimens, likely plays important roles in predicting the clinical prognosis of gastric cancer patients.

Furthermore, many signaling pathways have been associated with chemotherapy resistance, including the Wnt signaling pathway (36-40). Previous studies indicated that dysregulation of the Wnt/ $\beta$-catenin signaling pathway is involved in pancreatic cancer chemoresistance (39). Accumulating research indicates that Lgr5 is a target of Wnt signaling (5-8). Lgr5 becomes part of the Wnt signaling complex at the membrane level and enhances $\mathrm{Wnt} / \beta$-catenin signaling by increasing interactions with members of the Wnt pathway, including LRP6 and Fzd5 (8). Based on this, we speculate that Lgr5 may influence the sensitivity of gastric cancer cells to chemotherapeutic drugs via regulation of the Wnt signaling pathway.

In conclusion, our study demonstrated that elevated Lgr5 expression in gastric cancer following preoperative chemotherapy is significantly associated with tumor progression, poor pathological response to chemotherapy and shorter survival time. Furthermore, cytological analyses revealed that upregulation of Lgr5 may increase chemotherapy resistance in gastric cancer cells, while downregulation of Lgr5 was capable of sensitizing cells to chemotherapy. Therefore, Lgr5 may be a potential biomarker for predicting chemotherapeutic sensitivity and prognosis in gastric cancer patients and may represent a novel therapeutic target for cancer therapy.

\section{Acknowledgements}

This study was supported by grants from the National Natural Science Foundation of China (nos. 81272698, 81101883 and 81172368), a grant from PLA medical and health research fund project (no. 11BJZ17), a grant from PLA Medical Technology Key Project of Scientific Research in 12th Five-Year-Plan (no. BWS12J049), a grant form the Capital Health Research and Development of Special (no. 2011-5001-01), and a grant from the Major Science and Technology Project of 'National Significant New Drug Creation' from the Major Science and Technology of China (no. 2011ZX09307-001-05). 


\section{References}

1. Parkin DM, Bray F, Ferlay J and Pisani P: Global cancer statistics, 2002. CA Cancer J Clin 55: 74-108, 2005.

2. Thun MJ, DeLancey JO, Center MM, Jemal A and Ward EM: The global burden of cancer: priorities for prevention. Carcinogenesis 31: 100-110, 2010.

3. Cunningham D, Allum WH, Stenning SP, et al: Perioperative chemotherapy versus surgery alone for resectable gastroesophageal cancer. N Engl J Med 355: 11-20, 2006.

4. Becker K, Langer R, Reim D, et al: Significance of histopathological tumor regression after neoadjuvant chemotherapy in gastric adenocarcinomas: a summary of 480 cases. Ann Surg 253: 934-939, 2011.

5. Van der Flier LG, Sabates-Bellver J, Oving I, et al: The intestinal Wnt/TCF signature. Gastroenterology 132: 628-632, 2007.

6. Segditsas S, Sieber O, Deheragoda M, et al: Putative direct and indirect Wnt targets identified through consistent gene expression changes in APC-mutant intestinal adenomas from humans and mice. Hum Mol Genet 17: 3864-3875, 2008.

7. Yamamoto Y, Sakamoto M, Fujii G, et al: Overexpression of orphan G-protein-coupled receptor, Gpr49, in human hepatocellular carcinomas with beta-catenin mutations. Hepatology 37 528-533, 2003

8. Carmon KS, Lin Q, Gong X, Thomas A and Liu Q: LGR5 interacts and cointernalizes with Wnt receptors to modulate Wnt/3-catenin signaling. Mol Cell Biol 32: 2054-2064, 2012.

9. Barker N, van Es JH, Kuipers J, et al: Identification of stem cells in small intestine and colon by marker gene Lgr5. Nature 449: 1003-1007, 2007.

10. Jaks V, Barker N, Kasper M, et al: Lgr5 marks cycling, yet long-lived, hair follicle stem cells. Nat Genet 40: 1291-1299, 2008.

11. Barker N, Huch M, Kujala P, et al: Lgr5(+ve) stem cells drive selfrenewal in the stomach and build long-lived gastric units in vitro. Cell Stem Cell 6: 25-36, 2010.

12. Simon E, Petke D, Boger C, et al: The spatial distribution of $\mathrm{LGR}^{+}$cells correlates with gastric cancer progression. PLoS One 7: e35486, 2012.

13. Takahashi H, Ishii H, Nishida N, et al: Significance of Lgr5(+ve) cancer stem cells in the colon and rectum. Ann Surg Oncol 18: $1166-1174,2011$.

14. Kemper K, Prasetyanti PR, De Lau W, Rodermond H, Clevers H and Medema JP: Monoclonal antibodies against Lgr5 identify human colorectal cancer stem cells. Stem Cells 30: 2378-2386, 2012 .

15. Wu XS, Xi HQ and Chen L: Lgr5 is a potential marker of colorectal carcinoma stem cells that correlates with patient survival. World J Surg Oncol 10: 244, 2012.

16. McClanahan T, Koseoglu S, Smith K, et al: Identification of overexpression of orphan $\mathrm{G}$ protein-coupled receptor GPR49 in human colon and ovarian primary tumors. Cancer Biol Ther 5: 419-426, 2006

17. Tanese K, Fukuma M, Yamada T, et al: G-protein-coupled receptor GPR49 is up-regulated in basal cell carcinoma and promotes cell proliferation and tumor formation. Am J Pathol 173: 835-843, 2008.

18. Becker L, Huang Q and Mashimo H: Lgr5, an intestinal stem cell marker, is abnormally expressed in Barrett's esophagus and esophageal adenocarcinoma. Dis Esophagus 23: 168-174, 2010.

19. Nakata S, Campos B, Bageritz J, et al: LGR5 is a marker of poor prognosis in glioblastoma and is required for survival of brain cancer stem-like cells. Brain Pathol 23: 60-72, 2013.

20. Vermeulen L, Todaro M, de Sousa Mello F, et al: Single-cell cloning of colon cancer stem cells reveals a multi-lineage differentiation capacity. Proc Natl Acad Sci USA 105: 13427-13432, 2008.
21. Becker L, Huang $\mathrm{Q}$ and Mashimo H: Immunostaining of Lgr5, an intestinal stem cell marker, in normal and premalignant human gastrointestinal tissue. ScientificWorldJournal 8: 1168-1176, 2008.

22. Saigusa S, Inoue $\mathrm{Y}$, Tanaka $\mathrm{K}$, et al: Clinical significance of LGR5 and CD44 expression in locally advanced rectal cancer after preoperative chemoradiotherapy. Int J Oncol 41: 1643-1652, 2012.

23. Saigusa S, Inoue Y, Tanaka K, et al: Significant correlation between LKB1 and LGR5 gene expression and the association with poor recurrence-free survival in rectal cancer after preoperative chemoradiotherapy. J Cancer Res Clin Oncol 139: 131-138, 2013.

24. Ozkan M, Akbudak IH, Deniz K, et al: Prognostic value of excision repair cross-complementing gene 1 expression for cisplatin-based chemotherapy in advanced gastric cancer. Asian Pac J Cancer Prev 11: 181-185, 2010.

25. Oken MM, Creech RH, Tormey DC, et al: Toxicity and response criteria of the Eastern Cooperative Oncology Group. Am J Clin Oncol 5: 649-655, 1982.

26. Becker K, Mueller JD, Schulmacher C, et al: Histomorphology and grading of regression in gastric carcinoma treated with neoadjuvant chemotherapy. Cancer 98: 1521-1530, 2003.

27. Xi HQ, Wu XS, Wei B and Chen L: Aberrant expression of EphA3 in gastric carcinoma: correlation with tumor angiogenesis and survival. J Gastroenterol 47: 785-794, 2012.

28. Xi HQ, Zhao P and Han WD: Clinicopathological significance and prognostic value of LRP16 expression in colorectal carcinoma. World J Gastroenterol 16: 1644-1648, 2010.

29. Matsubara J, Yamada Y, Nakajima TE, et al: Clinical significance of insulin-like growth factor type 1 receptor and epidermal growth factor receptor in patients with advanced gastric cancer. Oncology 74: 76-83, 2008.

30. Wood LD, Calhoun ES, Silliman N, et al: Somatic mutations of GUCY2F, EPHA3, and NTRK3 in human cancers. Hum Mutat 27: 1060-1061, 2006.

31. Livak KJ and Schmittgen TD: Analysis of relative gene expression data using real-time quantitative PCR and the $2^{-\Delta \Delta C_{\mathrm{T}}}$ method. Methods 25: 402-408, 2001.

32. Lordick F, Stein HJ, Peschel C and Siewert JR: Neoadjuvant therapy for oesophagogastric cancer. Br J Surg 91: 540-551, 2004.

33. Al-Hajj M: Cancer stem cells and oncology therapeutics. Curr Opin Oncol 19: 61-64, 2007.

34. Dirks PB: Cancer: stem cells and brain tumours. Nature 444 687-688, 2006

35. Setoguchi T, Taga T and Kondo T: Cancer stem cells persist in many cancer cell lines. Cell Cycle 3: 414-415, 2004.

36. Haq R and Zanke B: Inhibition of apoptotic signaling pathways in cancer cells as a mechanism of chemotherapy resistance. Cancer Metastasis Rev 17: 233-239, 1998.

37. Gu L, Findley HW, Zhu N and Zhou M: Endogenous TNFalpha mediates cell survival and chemotherapy resistance by activating the PI3K/Akt pathway in acute lymphoblastic leukemia cells. Leukemia 20: 900-904, 2006.

38. Mahon KL, Henshall SM, Sutherland RL and Horvath LG: Pathways of chemotherapy resistance in castration-resistant prostate cancer. Endocr Relat Cancer 18: R103-R123, 2011.

39. Cui J, Jiang W, Wang S, Wang L and Xie K: Role of Wnt/ $\beta$-catenin signaling in drug resistance of pancreatic cancer. Curr Pharm Des 18: 2464-2471, 2012.

40. Zhang H, Zhang X, Wu X, et al: Interference of Frizzled 1 (FZD1) reverses multidrug resistance in breast cancer cells through the Wnt// $\beta$-catenin pathway. Cancer Lett 323: 106-113, 2012. 